\title{
Naturaleza de las concepciones que tienen los padres acerca de las aptitudes sobresalientes y su desarrollo en dos contextos socioculturales del Estado de Morelos, México ${ }^{1}$
}

Emma Isabel Soriano Martínez ${ }^{2}$ y Doris Castellanos Simons ${ }^{2}$

\section{Introducción}

La excepcionalidad relacionada con el alto potencial intelectual que manifiestan ciertos alumnos en los contextos educativos ha retomado importancia en México con la propuesta de intervención: "Atención educativa a alumnos y alumnas con aptitudes sobresalientes" (SEP, 2006), que está sustentada en modelos explicativos socioculturales en los que se concibe que el desarrollo de las aptitudes sobresalientes y los talentos específicos requieren un entorno facilitador y generador de influencias educativas que los potencien en contextos considerados clave, como la escuela, los grupos sociales y, en particular, el contexto familiar (Gagné, 2010; Mönks y Boxtel, 2006).

1 Este trabajo reporta resultados parciales de una tesis de maestría dirigida por la doctora Doris Castellanos Simons, con el apoyo del proyecto: "Influencia del apoyo familiar y variables asociadas sobre el logro académico en tres contextos educativos en Morelos y Sonora" (Proyecto No. 151981, financiado por el Consejo Nacional de Ciencia y Tecnología (CONACYT), cuyo responsable técnico es el doctor Aldo Bazán Ramírez, en la Universidad Autónoma del Estado de Morelos).

2 Universidad Autónoma del Estado de Morelos. 
Estudios actuales están investigando de manera creciente las necesidades de las familias en relación con la problemática del desarrollo de las aptitudes sobresalientes en sus hijos, que a menudo están sustentadas en los estereotipos y concepciones que tienen los padres acerca de su excepcionalidad, y de los eventos que promueven o dificultan el desarrollo de tales aptitudes sobresalientes (Borges, Hernández y Rodríguez, 2006; López, 2003; Soriano, 2013). Al respecto, Martínez y Guirardo (2010) destacan que algunos de los estereotipos manifestados con mayor frecuencia por las familias que tienen hijos con altas capacidades o aptitudes sobresalientes pueden clasificarse en las siguientes categorías: problemas escolares (la escuela no solventa las necesidades de los alumnos), problemas de interacción social (falta de afinidad con sus pares) y problemas del desarrollo emocional y cognitivo (disincronía), entre otros. Para López (2003), la existencia de estos estereotipos genera necesidades en los padres que se centran en las carencias concretas de información y orientación acerca de aspectos, como: el desfase existente entre el desarrollo intelectual y socioemocional del niño sobresaliente, la detección temprana del potencial sobresaliente en el hogar, las pautas para su educación, las diferencias entre potencial y rendimiento académico (fracaso escolar), la estimulación intelectual, la multipotencialidad, entre otros.

Un estudio de las concepciones que sustentan los padres de familia desde el enfoque cualitativo permitiría indagar las formas en que el fenómeno -en este caso las aptitudes sobresalientes- es percibido e interpretado por las personas (Pozo et al., 2006), y con ello se aportaría una mayor comprensión acerca de su impacto en las prácticas educativas parentales, y de su influencia en el propio desarrollo de los hijos y de sus potencialidades. Lo anterior permitiría conocer concretamente cómo los padres afrontan los retos de la excepcionalidad en sus hijos. Por otra parte, un estudio sustentado en un enfoque sociocultural permitiría distinguir las necesidades de orientación de las familias en diversos contextos y, con ello, generar estrategias de intervención acordes a las condiciones y necesidades reales que presentan. 
La finalidad del presente trabajo fue precisamente examinar la naturaleza de las concepciones y los estereotipos que tienen los padres acerca de las aptitudes sobresalientes y su desarrollo en dos contextos socioculturales del estado de Morelos.

\section{Método}

Es un estudio cualitativo centrado en obtener comprensión acerca de las visiones de los padres expresadas en sus concepciones y estereotipos respecto al desarrollo de aptitudes sobresalientes en sus hijos en contextos diferentes.

\section{Participantes}

Participaron voluntariamente 29 padres y madres de familias (22 mujeres y 7 hombres), 8 de un contexto semiurbano y 21 de un contexto urbano, cuyos hijos fueron previamente identificados en dos secundarias públicas como alumnos con aptitud sobresaliente en el área intelectual (un total de 105 alumnos fueron detectados, 30\% de la población).

\section{Material}

Para la recolección de datos se utilizó una entrevista semiestructurada conformada por cuatro temas ejes relacionados con las aptitudes sobresalientes: ¿Quiénes son los alumnos con aptitudes sobresalientes?, ¿qué tipos de apoyo deben recibir?, ¿qué tipo de apoyo se les debe brindar como padres?, ¿qué limitantes existen para el desarrollo de las aptitudes sobresalientes en el lugar donde viven?

\section{Procedimiento}

Las entrevistas se realizaron individualmente con una duración de 50 a 70 minutos cada una; al finalizarlas fueron transcritas. Para el procesamiento de los datos se realizó un análisis de contenido a 
nivel descriptivo del que emergieron categorías que integran en los diversos aspectos explorados la naturaleza de sus concepciones.

\section{Resultados}

Los resultados muestran que los padres sustentan cuatro tipos de concepciones respecto al desarrollo de las aptitudes sobresalientes (AS), a pesar de que existe variabilidad en aspectos específicos de su manifestación. Se describen a continuación y se ilustran con fragmentos de respuestas relacionadas con cada una, en los dos contextos analizados.

\section{Concepciones de tipo 1. Centradas en lo innato}

Se consideran las As como heredadas, presentes en una pequeña parte de la población, vinculándose con la inteligencia como algo homogéneo que se manifiesta en la resolución de problemáticas académicas fundamentalmente. Ejemplos:

"La aptitud sobresaliente es tener una inteligencia superior al promedio y la capacidad de resolver problemas por esa misma aptitud de hacer cosas, que los demás no podrían" (madre, urbano).

"[...] es todo lo que él trae por nacimiento, porque es por nacimiento que lo traen, no se aprende en los libros, nunca les leemos [...]" (madre, urbano).

Concepciones de Tipo 2. Centradas en la influencia del ambiente.

Se les concibe en múltiples dimensiones: inteligencia, habilidades, participación, rendimiento académico, intereses, rasgos de personalidad, etcétera. Las As se desarrollan en el sujeto como respuesta a la acción de influencias y agentes educativos: el docente y/o la familia, principalmente. Los padres se involucran activamente en el proceso y lo determinan en amplio sentido, de ellos depende motivar, incentivar y desarrollar estrategias definitorias. Ejemplos: 
"[En la escuela] es donde pudieran los maestros desarroIlar las habilidades de estas personas para encauzarlas hacia un bien, que pudieran ser líderes" (madre, urbano).

"[...] le debo comprar libros o cosas que le sirvan a ella para que desarrolle su capacidad" (madre, semiurbano).

Concepciones de tipo 3. Centradas en el carácter activo del sujeto

Se reconoce la diversidad en cuanto a áreas en que se manifiestan las aptitudes (áreas particulares). Las aptitudes pueden ser heredadas o conformadas bajo la influencia de los factores del ambiente familiar, pero sobre todo su desarrollo va a depender del propio sujeto, de su capacidad para autorregularse y autodesarrollar su potencial a pesar de no tener en ocasiones ayuda externa por parte de los demás y de la sociedad. Los alumnos con As se identifican por su alta capacidad de aprendizaje, autodidactismo, rendimiento y liderazgo. Ejemplos:

"Para hacer un proyecto son los que toman iniciativa y dicen '¡lo hacemos!', y pues sí, son los que tienen más confianza para hacer las cosas" (madre, semiurbano).

"Depende de cada niño, quien quiera estudiar, quien no, quien quiere aprender, más que nada, la actitud" (madre, contexto semiurbano).

Concepciones de tipo 4. Centrada en la naturaleza interactiva del desarrollo de las As

Las As se van a manifestar en los alumnos a través de rasgos volitivos e intereses focalizados en el área académica y otras. El alumno con As, el docente y la familia desempeñan un rol activo conjunto, y es de la interacción entre sus esfuerzos e influencias que estas aptitudes se desarrollan, siendo también muy importante la implicación del sujeto en este proceso. La falta de involucramiento y la falta de interés o capacitación de los padres, escuela y/o el desinterés del alumno obstaculizan el desarrollo de su potencial sobresaliente. Ejemplo: 
"Pienso que todos tenemos la capacidad, que a algunos se les da más, pero hay que trabajar, hay que desarrollarlos, hay que trabajarlos desde pequeños [...] y así sucesivamente, hay que darles las oportunidades a nuestros hijos de que hagan actividades que desarrollen la inteligencia o las habilidades que tengan [...]" (madre, semiurbano).

Por otra parte, existen diferencias en los tipos de concepciones que tienen los padres en cada uno de los contextos: en el contexto semiurbano se presentan con mayor frecuencia concepciones del tipo 2, 3 y 4, mientras que en el urbano de tipo 1 y 2.

Asimismo, tales concepciones se vinculan con cinco tipos de estereotipos:

1) El alumno sobresaliente va a mostrar excepcionalidad en todo lo que realice; 2) No requiere apoyo para desarrollar sus aptitudes; 3) Las aptitudes sobresalientes del alumno siempre son innatas; 4) Es siempre muy inteligente; 5) Suelen quedarse siempre por debajo de su potencial de rendimiento debido a la falta de respuestas a sus necesidades educativas, por lo que necesitan atención especializada.

\section{Discusión}

A partir de las diferencias encontradas en los tipos de concepciones de los padres acerca de las aptitudes sobresalientes y su desarrollo en los dos escenarios explorados, puede inferirse que el contexto sociocultural va a ser un elemento que influye en su construcción (Pozo et al., 2006). En el contexto urbano analizado, más favorecido socioeconómicamente, se percibe mayormente la aptitud sobresaliente como algo innato, dándose mucha importancia a la inteligencia, lo que puede relacionarse con aspectos culturales como la sobrevaloración de ésta en los procesos selectivos de tránsito de los niños dentro de los diferentes niveles educativos y en el acceso a experiencias educativas de calidad. Los padres del contexto semiurbano parecen atribuir mayor importancia a la ayuda del entorno (escuelas, instituciones) para el desarrollo del potencial en sus hijos, al valor del propio esfuerzo y 
de las actitudes individuales en los alumnos, así como a la detección de habilidades más heterogéneas que permitirán a sus hijos el acceso a escuelas técnicas o a algún oficio, lo que representa menor inversión familiar en tiempo y costos, y un medio para aportar económicamente a la familia.

Las concepciones que tienen los padres son variadas, sólo algunas coinciden con modelos como el de Gagné (2010) que ven la transformación de las aptitudes a talentos como un proceso de desarrollo en que se entrelaza la influencia de los catalizadores y mediadores personales con el de los factores ambientales. No obstante, a pesar de la diversidad de visiones y estereotipos encontrados, que corresponden con lo planteado por Martínez y Guirardo (2010), todos los padres manifiestan la necesidad de ser orientados para un mejor conocimiento de las necesidades educativas y socioemocionales de sus hijos con el fin de generar un contexto familiar facilitador para su desarrollo; perciben como sus principales limitaciones la falta de recursos económicos y educativos.

Para finalizar, puede decirse que así como plantean autores como Borges y otros (2006), los padres perciben su rol centrado en funciones fundamentales: apoyo socioemocional, soporte económico, enriquecimiento cultural, guía del desarrollo personal y orientación para el desarrollo de habilidades y desarrollo académico de sus hijos.

A pesar de las limitaciones del tamaño de la muestra y la incorporación de sólo dos contextos -lo que no refleja toda la complejidad y diversidad de esta dimensión-, este estudio destaca la importancia de investigaciones desde la visión sociocultural para una mayor comprensión del desarrollo de este alumnado y del impacto de la familia y la escuela en éste.

\section{Referencias}

Borges, A., Hernández, C. y Rodríguez, E. (2006). Comportamientos parentales en familias con superdotados. Faísca, 11(13), 48-58. 
Gagné, F. (2010). Defining Academic Talent Development Through the DMGT. Ideación, 33, 425-441.

López, M. (2003). Análisis de las características y necesidades de las familias con hijos de superdotados: propuesta y evaluación de un programa de intervención psicoeducativa en el contexto familiar. Tesis de doctorado, Universidad complutense de Madrid. Recuperado de http://eprints.ucm. es/tesis/edu/ucm-t26461.pdf.

Martínez, M. y Guirardo, A. (2010). Alumnados con altas capacidades. Barcelona: Graó.

Mönks, F. y Boxtel, H. (2006). Adolescentes superdotados: una perspectiva evolutiva. En J. Freeman. Los niños superdotados. Aspectos pedagógicos y psicológicos (Trad. M. Illueca) (pp. 306-324). Madrid: Santillana.

Pozo, J., Scheuer, N., Pérez, M., Marcos, M., Martín, E. y De la Cruz, M. (2006). Nuevas formas de pensar la enseñanza y el aprendizaje: Las concepciones de profesores y alumnos. España: Graó.

SEP (2006). Propuesta de intervención: Atención educativa a alumnos y alumnas con aptitudes sobresalientes. México: Secretaría de Educación Pública.

Soriano, E.I. (2013). Concepciones de docentes y padres acerca de las aptitudes sobresalientes: Un estudio sociocultural en Morelos. Tesis para defender el título de Licenciada en Psicología (inédita). Universidad Autónoma del Estado de Morelos, México. 